\title{
A Note on Electric Potential Gradient Measurements Near Icelandic Geyser and Steam Plume from Geothermal Well
}

\author{
SVEINBJÖRN BJÖRNSSON \\ The State Electricity Authority, Reykjavik, Iceland \\ AND BERNARD VONNEGUT \\ Arthur D. Little, Inc., Cambridge, Mass.
}

7 December 1964

Schaefer et al. (1963) have reported observations of the atmospheric electrical effects attending the eruptions of Old Faithful and other geysers in Yellowstone National Park. It was their finding that usually the eruption produced only minor electrical perturbations, reducing the fair weather field perceptibly but only rarely reversing it.

We had the opportunity of carrying out similar measurements in the Hengill geothermal area about $50 \mathrm{~km}$ southeast of Reykjavik, Iceland. Here, using a polonium probe attached to a portable vacuum tube electrometer we have investigated electrical perturbations produced by a small geyser and by the high velocity steam and water plumes coming from one of the geothermal wells that have been bored by the State Electricity Authority for electric power production. During the eruption of one of the minor geysers, considerably smaller than Old Faithful, the polonium probe was held about $2 \mathrm{~m}$ above the ground and about $10 \mathrm{~m}$ away from the steam and water plume. No detectable electrical perturbation was observed. This finding duplicates the experience of one of the authors who did not observe any perturbations to be associated with small geysers in Yellowstone Park.

In contrast to the geyser the high velocity steam plume from the geothermal well was intensely electrified. Fig. 1 is a schematic diagram of well number eight, which was investigated. At full flow this well produces $65 \mathrm{~kg} \mathrm{sec}^{-1}$ of liquid water and $31 \mathrm{~kg} \mathrm{sec}^{-1}$ of steam at about $6 \mathrm{~atm}$ gage pressure. The centrifugal separator is used to remove most of the liquid water from the steam. Fig. 2 shows the appearance of the plumes as 


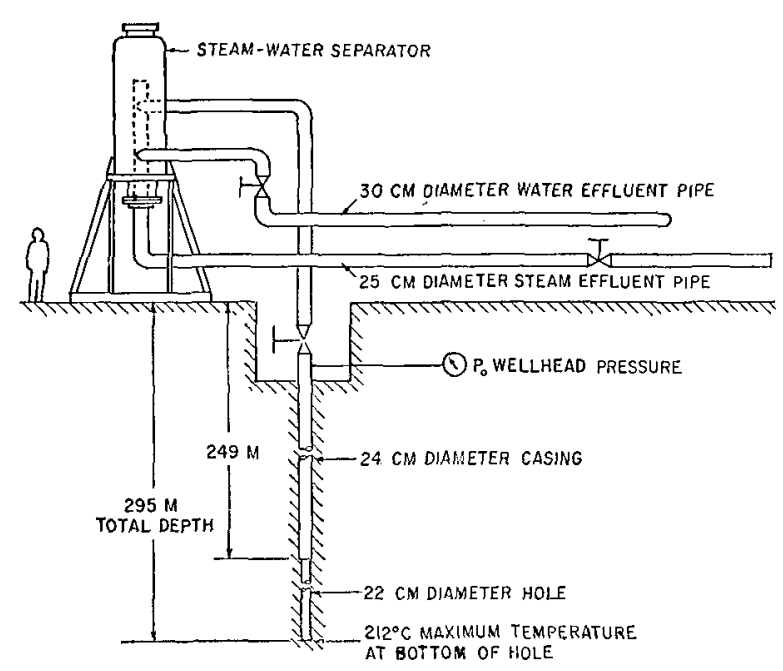

FIG. 1. Schematic diagram of geothermal well.

they leave the well. The steam is on the right and the hot water is on the left.

During our measurements the electrometer and probe were held 8 meters horizontally distant from the outlet of the steam effluent pipe and at a height of $0.5 \mathrm{~m}$ above the ground. At this location when the steam was flowing, the polonium probe was about $1 \mathrm{~m}$ from the surface of the steam plume, which at this point was about $3 \mathrm{~m}$ in diameter.

Before the steam was turned on, the electrometer indicated a fair weather potential gradient about $1 \mathrm{v}$ $\mathrm{cm}^{-1}$. As the valve of the well was opened, the gradient began to increase but readings were erratic because the cloud was blown around by the wind. When the pressure in the steam pipe reached about 0.5 atm gage, the steam jet became stable and the electrometer indicated a steady gradient of approximately $100 \mathrm{v} \mathrm{cm}^{-1}$. Further opening of the valve and the consequent increase in the flow of steam did not produce an increase in the electric gradient.

- Very little electrification was observed near the pipe opening where the effluent hot water at $140 \mathrm{C}$ flashed partly to steam. The electrometer indicated a gradient of only $4 \mathrm{v} \mathrm{cm}^{-1} 1$ meter from the plume, 1 meter above the ground and 3 meters from the pipe outlet.

In order to determine if the electrification were being produced in the centrifugal separator, we made measurements on the steam before it entered this apparatus. We found that a jet of this steam of 0.5 atmosphere gage pressure coming out of a vertical pipe $2.5 \mathrm{~cm}$ diameter produced a gradient of $40 \mathrm{v} \mathrm{cm}^{-1}$ near the outlet. During periods when slugs of water came out, the electrification ceased.

It is interesting that the steam plume from the well

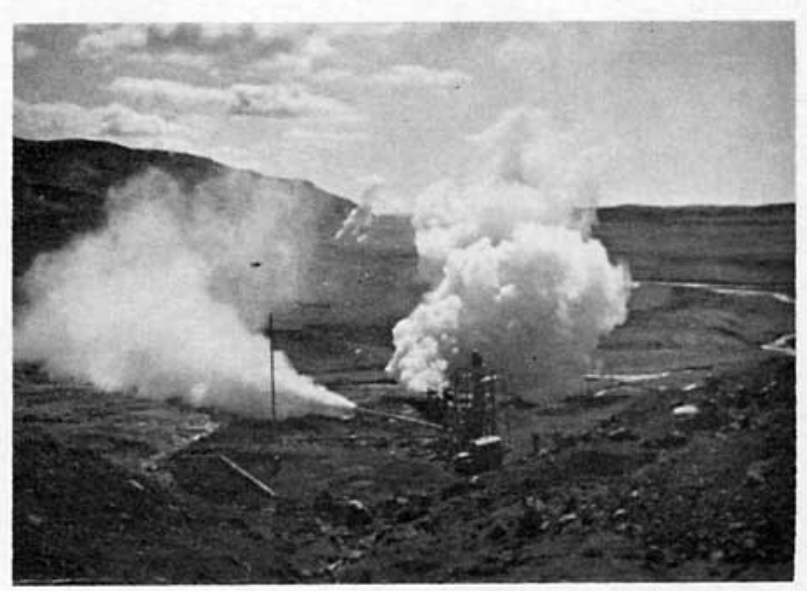

Fig. 2. Effluent from geothermal well. Water plume is on the left and steam plume on the right.

is highly electrified while the steam from geysers is not. Perhaps our observations of the weak potential gradients near the plume from the water effluent pipe may provide some clue to the reasons for this difference. Here the condition of an extremely high liquid water content is probably much closer to that in a geyser than in the steam effluent pipe or in the untreated steam. It seems possible that when there is a very high concentration of liquid water with the steam. travelling in a pipe or subterranean tube it may interfere with the steam electrification process investigated by Faraday (1844) and others. Perhaps a continuous film of water on the walls of the conduit prevents contact electrification. Alternatively perhaps the electrification produced by the steam is neutralized by electrically continuous filaments of water that may form. The details of the electrification process and how it is influenced by various factors appear worthy of further investigations.

Acknowledgments. The authors wish to take this opportunity to thank their colleagues, Stefan Sigurmundsson of the Vermir s.f. and Barrie McLean of the American Meteorological Society for their help in making these measurements. We also thank The State Electricity Authority, the U. S. Office of Naval Research, the National Science Foundation and Arthur D. Little, Inc., for their support of this work.

\section{REFERENCES}

Faraday, M., 1844: On the electricity evolved by the friction of water and steam against other bodies. Exporimental $R e-$ searches into Electricity, Vol. II, 18th series, 106-126.

Schaefer, V. J., and B. Vonnegut, 1963 : Electric field perturbations caused by eruption of Yellowstone geysers. $J$. Almos. Sci., 20, 18-182. 